\title{
Christopher W. Thompson, Explorations stendhaliennes. D"'Armance" à la «Fraternité des arts»
}

\section{Michel Arrous}

\section{(2) OpenEdition}

1 Journals

\section{Édition électronique}

URL : http://journals.openedition.org/studifrancesi/1544

DOI : 10.4000/studifrancesi. 1544

ISSN : 2421-5856

Éditeur

Rosenberg \& Sellier

\section{Édition imprimée}

Date de publication : 1 novembre 2014

Pagination : 616

ISSN : 0039-2944

\section{Référence électronique}

Michel Arrous, «Christopher W. Thompson, Explorations stendhaliennes. D"Armance" à la «Fraternité des arts» », Studi Francesi [En ligne], 174 (LVIII | III) | 2014, mis en ligne le 01 novembre 2014, consulté le 18 septembre 2020. URL : http://journals.openedition.org/studifrancesi/1544; DOI : https://doi.org/ 10.4000/studifrancesi. 1544

Ce document a été généré automatiquement le 18 septembre 2020.

\section{(c)}

Studi Francesi è distribuita con Licenza Creative Commons Attribuzione - Non commerciale - Non opere derivate 4.0 Internazionale. 


\title{
Christopher W. Thompson, Explorations stendhaliennes. D"Armance" à la «Fraternité des arts»
}

\author{
Michel Arrous
}

\section{RÉFÉRENCE}

CHRISTOPHER W. THOMPSON, Explorations stendhaliennes. D"“Armance" à la «Fraternité des arts», Paris, Hermann, 2013, pp. 677.

Depuis plus de trente ans $\mathrm{C}$. W. Thompson s'est attaché à analyser certains thèmes stendhaliens dont l'importance apparaît de manière plus évidente dans ce recueil où sont regroupées des études entièrement nouvelles, mais aussi des pages corrigées, adaptées et mises à jour pour tenir compte des dernières recherches. D'abord, deux importantes sections consacrées à l'étude des structures et des stratégies dans les romans et les nouvelles: «De De l'Amour à Lamiel» et «Des Singularités à Armance» (pp. 15-287), suivies de deux autres: dans «Stendhal et la "Fraternité des arts"» (pp. 291-426).Thompson, qui a une connaissance approfondie de l'abondante critique des Salons, traite de la participation de Stendhal aux débats sur la peinture: dans Des manuscrits aux livres sont analysés, du point de vue esthétique et typographique, quelques aspects de l'activité ou de la graphomanie scripturaire de Stendhal, par exemple les notes en bas de page ou les soulignés dans les livres du fonds Bucci. Si l'Armancie est un des territoires favoris de Thompson qui a interrogé l'ambivalence d'Octave en mettant en évidence le rôle important des figures de Byron et de Shelley, d'autres pans de l'œuvre de Stendhal ne sont pas négligés. Ainsi, la brève étude Désinvolture et sacralisation ludiques chez Stendhal dans "De l'Amour" permet de montrer que dans ce livre si important pour Stendhal, mais qui ne fut pas l'objet de beaucoup de soins de sa part pendant la fabrication, l'idée du jeu est souvent présente. Suit l'étude bien connue (1979) intitulée L'armée ou l'église: sur les ressorts latents du dilemme héroïque chez Stendhal: d"AArmance" à "La Chartreuse de Parme", consacrée à l'alternative des deux 
carrières et à leurs séductions. Les héros des quatre grands romans «évoluent à l'ombre du mythe du prêtre guerrier non moins qu'à l'ombre du mythe du héros conquérant», mais la réconciliation du sacerdoce et du métier des armes est impossible. Dans Conflit, genre et transcendance dans "Le Rouge et le Noir", l'auteur, plutôt que de reprendre l'étude classique des conflits politiques a choisi leurs aspects «genrés» dans le comportement des personnages. Contrairement aux fréquentes lectures expéditives des fins de Stendhal, Thompson démontre qu'elles sont quasiment surdéterminées (Sur les fins des récits de Stendhal). Mentionnons aussi De la caricature et des énergies de la classe montante dans "Lamiel": Stendhal, Balzac et les "Mayeux" qui revient sur la figure de Mayeux et à son «irrésistible» comparaison avec Sansfin. On lira ou relira avec profit les pages sur les récits courts, par exemple Le Chevalier de Saint-Ismier, ou sur l'évolution de l'intérêt de Stendhal pour Casanova, cet autre égotiste jugé inférieur car il n'y avait chez lui ni désir ni volonté de transgression. Complété par une riche bibliographie et un index, ce beau recueil s'ajoute aux deux ouvrages qui ont fait date, Le Jeu de l'ordre et de la liberté dans "La Chartreuse de Parme" (1982, reprint Slatkine, 2011) et "Lamiel" fille du feu (1997). 